\title{
A importância das ligas acadêmicas no processo de integração e acolhimento do ingressante no curso de medicina: Relato de experiência
}

The importance of the academic leagues in the integration and reception process of the incomingmedical student: Experience report

La importancia de las ligas académicas en el proceso de integración y acogida del ingresante en el curso de medicina: Relato de experiencia

Ana Luíza Brum Reis Soares ${ }^{1}$, Carolina Baptista Amorim Rocha ${ }^{1}$, Diego Silva Vieira ${ }^{1}$, Lucas Fernandes Crahim¹, Maurício Leal Martins', Paula Pitta de Resende Côrtes ${ }^{2}$

Como citar esse artigo. Soares, ALBR; Rocha, CBA; Vieira, DS; Crahim, LF; Martins, ML; Côrtes, PPR. A importância das ligas acadêmicas no processo de integração e acolhimento do ingressante no curso de medicina: Relato de experiência. Revista Pró-UniverSUS. 2019 Jan./Jun.; 10 (1): XX-XX

\section{Resumo}

As ligas acadêmicas são formadas por um grupo de alunos e professores com interesses em comum, objetivando aprofundar certos temas, elaborar projetos de pesquisa, ensino e extensão, levando à integração de alunos de diferentes períodos. Para o aluno ingressante, o início da vida acadêmica é marcado por novos desafios e angustias e dessa forma, um grupo de alunos, junto com a coordenação do curso de Medicina, elaborou o Programa de Acolhimento ao Ingressante, um evento que objetiva recepcionar os novos alunos. Durante o evento ocorre a feira da calourada, e esta tem como objetivo apresentar as ligas acadêmicas e integrar os ingressantes do curso. Este trabalho trata-se do relato de experiência de uma feira de ligas acadêmicas. As ligas participantes tiveram a liberdade de escolher quais atividades seriam apresentadas. Os alunos ingressantes se mostraram dispostos a interagir com seus veteranos e a conhecer as atividades propostas por cada liga. Três meses após o evento, foi aplicado questionário sobre as atividades realizadas. O evento representou experiência positiva trazendo interação entre calouros e veteranos, pois permitiu o contato das ligas com alunos de perfis diferentes já no segundo dia de curso. Após análise das respostas ao questionário, foi possível perceber que os alunos consideram as ligas como uma importante forma de integração entre os acadêmicos e um meio de aproximação à pratica médica. A feira da calourada aproximou precocemente os alunos ingressantes de seus veteranos e amenizou dúvidas e angústias em relação ao ingresso na faculdade.

Palavras-chave: Educação Médica; Educação em Saúde; Estudantes de Medicina.

\begin{abstract}
Academic leagues are formed by a group of students and teachers with commoninterests, aiming to deepen certain themes, to elaborate research projects, teaching and extension, leading to the integration of students from different periods. For the incoming student, the beginning of academic life is marked by new challenges and anguish, thus, a group of students, together with the coordinator of the medical school, prepared the Program for Reception to the Incoming Student, an event that aims to welcome the new students. During the event the fair of the freshmen takes place, and this one has as objective to present the academic leagues and to integrate the incoming ones of the course. This paper is about the experience report of an academic leagues fair. Participating leagues were free to choose which activities would be presented. The incoming students were willing to interact with their veterans and learn about the activities proposed by each league. Three months after the event, a questionnaire was applied on the activities performed. The event represented a positive experience bringing interaction between freshmen and veterans, since it allowed the leagues to contact students of different profiles already on the beginning of the course. After analyzing the answers to the questionnaire, it was possible to perceive that students consider leagues as an important form of integration among the academics and a means of approaching medical practice. The freshman fair soon brought in the incoming students of their veterans and softened doubts and anguish about entering college.

Keywords: Education, Medical; Health Education; Students, Medical.
\end{abstract}

2. Docente do Curso de Medicina/Universidade de Vassouras/Vassouras/RJ/Brasil. 


\section{Resumen}

Las ligas académicas están formadas por un grupo de alumnos y profesores con intereses en común, con el objetivo de profundizar ciertos temas, elaborar proyectos de investigación, enseñanza y extensión, llevando a la integración de alumnos de diferentes períodos. Para el ingresante, el inicio de la vida académica contempla nuevos desafíos y angustias, de esa forma, un grupo de alumnos y la coordinación del curso de Medicina, elaboró el Programa de Acogimiento al Ingresante, un evento que objetiva recibir los nuevos estudiantes. Durante el evento ocurre la feria de la calurosa, y ésta tiene como objetivo presentar las ligas académicas e integrar los ingresantes del curso. Este trabajo se trata del relato de experiencia de una feria de ligas académicas. Las ligas participantes tuvieron la libertad de elegir qué actividades se presentar. Los alumnos ingresantes se mostraron dispuestos a interactuar con sus veteranos ya conocer las actividades de cada liga. Tres meses después del evento, se aplicó un cuestionario sobre las actividades realizadas. El evento representó experiencia positiva trayendo interacción entre caballeros y veteranos, pues permitió el contacto de las ligas con alumnos de perfiles diferentes ya en el segundo día de curso. Después del análisis de las respuestas al cuestionario, fue posible percibir que los alumnos consideran las ligas una importante forma de integración y un medio de aproximación a la práctica médica. La feria de la calurosa acercó precozmente a los alumnos ingresantes de sus veteranos y amenizó dudas y angustias en relación al ingreso en la facultad.

Palabras clave: Educación Médica; Educación em Salud; Estudiantes de Medicina

\section{Introdução}

As Ligas Acadêmicas (LA) estão cada vez mais presentes, como atividades extracurriculares, nos cursos de graduação pelo Brasil, principalmente nos cursos de Medicina. Configuram-se como entidades estudantis que, organizadas por um grupo de alunos, e orientadas por um ou mais professores, buscam se aprofundar em um determinado tema e atender as demandas da população ${ }^{1}$. Para alcançar esse objetivo é necessário que as ligas integrem atividades de ensino, pesquisa e extensão.

Nesses grupos, o estudante desenvolve e participa de atividades que ampliam seu conhecimento como aulas, palestras e simpósios; acompanha procedimentos e atendimentos na área de interesse; e atua junto à comunidade como agente promotor de saúde e transformador social através de feiras e campanhas de saúde. ${ }^{2}$ Esse conjunto de ações atende o que propõem as Diretrizes Curriculares Nacionais do Curso de Graduação em Medicina na resolução de 2014, quando resolve que o futuro profissional médico deve articular conhecimentos, habilidades e atitudes para atuar nos diferentes níveis de atenção à saúde, com ações de promoção, prevenção, recuperação e reabilitação da saúde, nos âmbitos individual e coletivo, com responsabilidade social como ator no processo saúde/doença ${ }^{3}$ permitindo ao aluno não somente o desenvolvimento científico, mas também o exercício da cidadania.

Participando de uma LA o estudante estabelece vínculo com alunos ligantes, alunos não-ligantes, professores e comunidade e se aproxima da prática médica em um cenário diversificado. ${ }^{4}$ Esse espaço, ainda pode ser utilizado para o desenvolvimento de atividades de ensino e pesquisa, no qual o graduando tem a possibilidade de melhorar sua análise crítica, maturidade intelectual, compreensão da ciência e possibilidades futuras, tanto acadêmicas como profissionais ${ }^{2,5}$ o que torna a LA uma excelente ferramenta para a flexibilização curricular, atribuindo características únicas à formação acadêmica de cada aluno de acordo com sua curiosidade científica e capacidade investigativa.

O ingresso em uma LA não é requisito obrigatório para a formação de futuros profissionais. No entanto, as universidades estimulam os estudantes a participarem desses grupos por promoverem uma formação embasada na realidade e incentivarem a capacidade de estímulo ao trabalho em equipe, à reflexão crítica e à autonomia dos estudantes através da autogestão do seu ensino. ${ }^{5}$

Sendo as ligas acadêmicas ferramentas de integração social e de iniciação científica, aqueles estudantes que acabaram de ingressar em um curso de graduação podem ser extremamente beneficiados. $\mathrm{O}$ ingresso no ensino superior é sempre marcado por desafios, relacionar-se com pessoas desconhecidas, ajustar-se a novas regras de comportamento e encarar diferentes responsabilidades. Esse período de ajuste pode ser amenizado pelo sentimento de pertencer a um grupo com ideias em comum, o que irá se tornar uma forma de rede de apoio. ${ }^{6}$ Deste modo, os membros mais experientes da LA podem ser a melhor fonte de informações para que o ingressante possa recorrer em caso de dificuldade. Dúvidas sobre como iniciar nas pesquisas científicas, regras de funcionamento do curso, oportunidades oferecidas pela universidade, entre outras, podem ser facilmente dirimidas através desse canal direto com os veteranos, que é a liga acadêmica. Contudo, o desconhecimento do ingressante sobre do que se trata uma LA ou como acessá-la ainda se constitui como uma dificuldade, que só é vencida após meses de permanência no curso, tempo esse que pode ser abreviado através de medidas ativas de integração deste aluno. 
Sendo assim, ao vivenciar e observar situações de desconforto, aflição e angústia, um grupo de alunos e a coordenação do curso de Medicina, assumiram o compromisso de tornar o ingresso na faculdade uma experiência agradável e o mínimo conturbada e solitária possível. Parte dessa estratégia consiste na feira da calourada, que está inserida em um projeto de recepção dos calouros.

Nos dois primeiros dias de aula são desenvolvidas atividades com os ingressantes no curso de Medicina dentrodo Programa deAcolhimento ao Ingressante(PAI). Este visa apresentar, acolher e orientar os alunos recém chegados, acerca dos desafios a serem enfrentados nesta nova etapa de suas vidas. Durante o PAI é desenvolvida a "feira da calourada"(Figura 1) que objetiva apresentar as atividades de ensino, pesquisa e extensão desenvolvidas por cada LA do curso de Medicina. As ligas são livres para demonstrar seu trabalho e valorizar a importância das atividades que desenvolvem a fim de conquistar a atenção do novo aluno que poderá em breve ingressar no(s) grupo(s) que mais tiver interesse. Neste sentido, este trabalho visa relatar a experiência dos membros envolvidos na realização da "feira da calourada" do Curso de Medicina da Universidade de Vassouras demonstrando a importância das LA no processo de integração e acolhimento do ingressante no curso de Medicina.

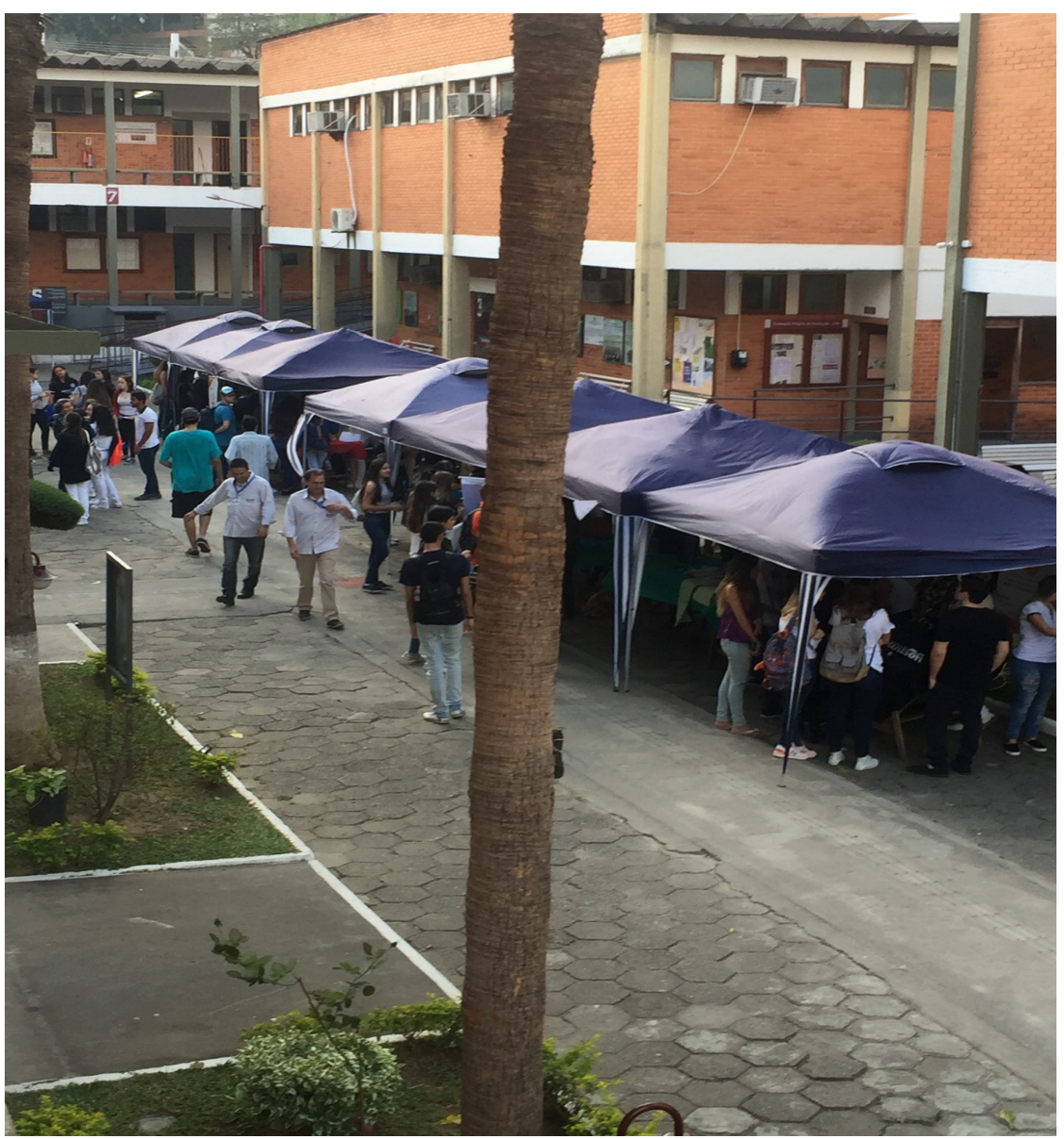

Figura 1. Feira da calourada no campus da universidade. 


\section{Materiais e Métodos}

Foi realizadaumarevisão bibliográfica, com levantamento nas bases de dados ScieLO, ResearchGate, Lilacs, e Portal do Ministério da Educação do Brasil. Foram utilizadas as palavras chave:ligas acadêmicas, ligas estudantis, educação médica e estudantes de medicina. Foram selecionados aqueles artigos que permitiam livre acesso do conteúdo na íntegra e que fossem relacionados ao tema, no total de onze.

Trata-se dorelato de experiência de uma feira acadêmica que está inserida no projeto de recepção dos ingressantes ao curso de Medicinada Universidade de Vassouras, o Programa de Acolhimento ao Ingressante (PAI). Este evento ocorre regularmente nos dois primeiros dias letivos do primeiro período do curso de Medicina. Para que este projeto alcance seu objetivo, a comissão organizadora, composta pela coordenação do curso e por alunos de diversos períodos, busca planejar atividades que abordem as dificuldades, angústias e anseios relatados pelos estudantes já veteranos e vivenciados pelos próprios alunos organizadores. Dentre as atividades desenvolvidas pelo PAI está a "feira da calourada". Esta ocorre na tarde do segundo dia do evento em tendas estruturadas nas dependências do campus universitário. Este relato de experiência se refere as atividades desenvolvidas no dia 24 de julho de 2018 .

Todas as LA do Curso de Medicina foram convidadas a participar através do diretório científico do Centro Acadêmico. A equipe do PAI selecionou aquelas que apresentaram uma melhor temática para os ingressantes: Liga de Anatomia Humana, Liga de Clínica Médica, Liga de Iniciação Científica, Liga de Nefrologia, Liga de Cirurgia Plástica, Liga de Medicina de Família e Comunidade, Liga de Psiquiatria, Liga de Pediatria, Liga Projeto Vidas (primeiros socorros), Liga de Transplante de Órgãos e Tecidos, Liga de Infectologia e Unidade de Dor torácica. Os membros das LAs selecionadas receberam orientação quanto ao dia, horário, local e espaço destinado à apresentação de suas atividades. Estes chegaram com antecedência de uma hora ao local para que organizassem o seu material.

A partir desse ponto as LA ficaram livres para expor seus trabalhos, criar atividades práticas, aplicar questionários, como assim desejassem.

Antes de autorizar os alunos para o acesso à feira, a comissão do PAI reuniu os ingressantes e explicou a que se propõe uma LA, seu papel na universidade e os benefícios acadêmicos e sociais que seus membros podem obter. Também os incentivou a buscarem informações em todas as tendas, sem se limitarem a sua área de interesse. Foram orientados também a interagir com os alunos de sua nova turma e com seus veteranos. Os alunos então, foram liberados para que percorressem as tendas sem ordem pré-definida de acordo com seus interesses.

Ao chegarem na "feira da calourada", os novos alunos foram recepcionados pelos membros das LA participantes e apresentados às atividades que desenvolvem, como simpósios, congressos e reuniões; os trabalhos apresentados em congressos e publicados em revistas científicas; feiras e campanhas de saúde na comunidade; além de abordagens mais dinâmicas e interativas com os visitantes. Houve encenação de uma parada cardiorrespiratória com simulação de ressuscitação cardiopulmonar (figura 2), demonstração de técnicas de sutura e os materiais (figura 3), jogos de perguntas e respostas com brindes para os participantes (figura 4), explicação sobre a percepção dos sinais de ansiedade pelo corpo (figura 5), demonstração de coleta de exame preventivo ginecológico em peça anatômica (figura 6), jogo de posicionamento do órgãos pelo corpo humano (figura 7), apresentação e demonstração de instrumentos e técnica laparoscópica (figura 8), entre outras. Todas essas atividades demonstravam a todo tempo a importância da feira no acolhimento e integração dos ingressantes com os novos colegas também recém chegados, com os seus veteranos e com a universidade. Isso, em um ambiente perfeitamente propício para tal, livre de constrangimentos ou preocupações, onde estavam à vontade para trocar experiências, fazer perguntas ou apenas observar.Com isso, foi obtida maior adesão da turma ao evento, visto que estavam sem a pressão de professores, notas ou carga horária.

Completados três meses após o início das aulas foi aplicado um questionário avaliando a opinião dos ingressantes sobre as atividades desenvolvidas na "feira da calourada" no início do semestre. Resolveuse permitir um tempo entre a execução do programa e a aplicação das perguntas, para que eles tivessem esse período para processar as informações acerca do tema, e eliminando os elementos euforia e ansiedade de ter que responder a perguntas logo no seu segundo dia de faculdade.

Dos 68 alunos que participaram da feira, 51 deles responderam ao questionário, já que a sua participação era voluntária. As perguntas foram as seguintes: 1-A Feira da Calourada (feira das ligas) contribuiu para o seu acolhimento e integração com o curso e os alunos? Com as opções sim ou não; 2-Como você considera as ligas acadêmicas como ferramenta de socialização e integração entre os alunos? Com as opções: não importante, importante ou muito importante; 3 -Nos itens abaixo, dê uma nota de 0 a 10 sobre o que te motivaria ou te motivou a ingressar em uma liga acadêmica. Sendo 0 (nada interessante) e 10 (muito interessante). Os itens eram: Aproximação da prática médica, integração com veteranos e novas amizades, aproximação com os professores, interesse em uma área específica da medicina e iniciação científica. 


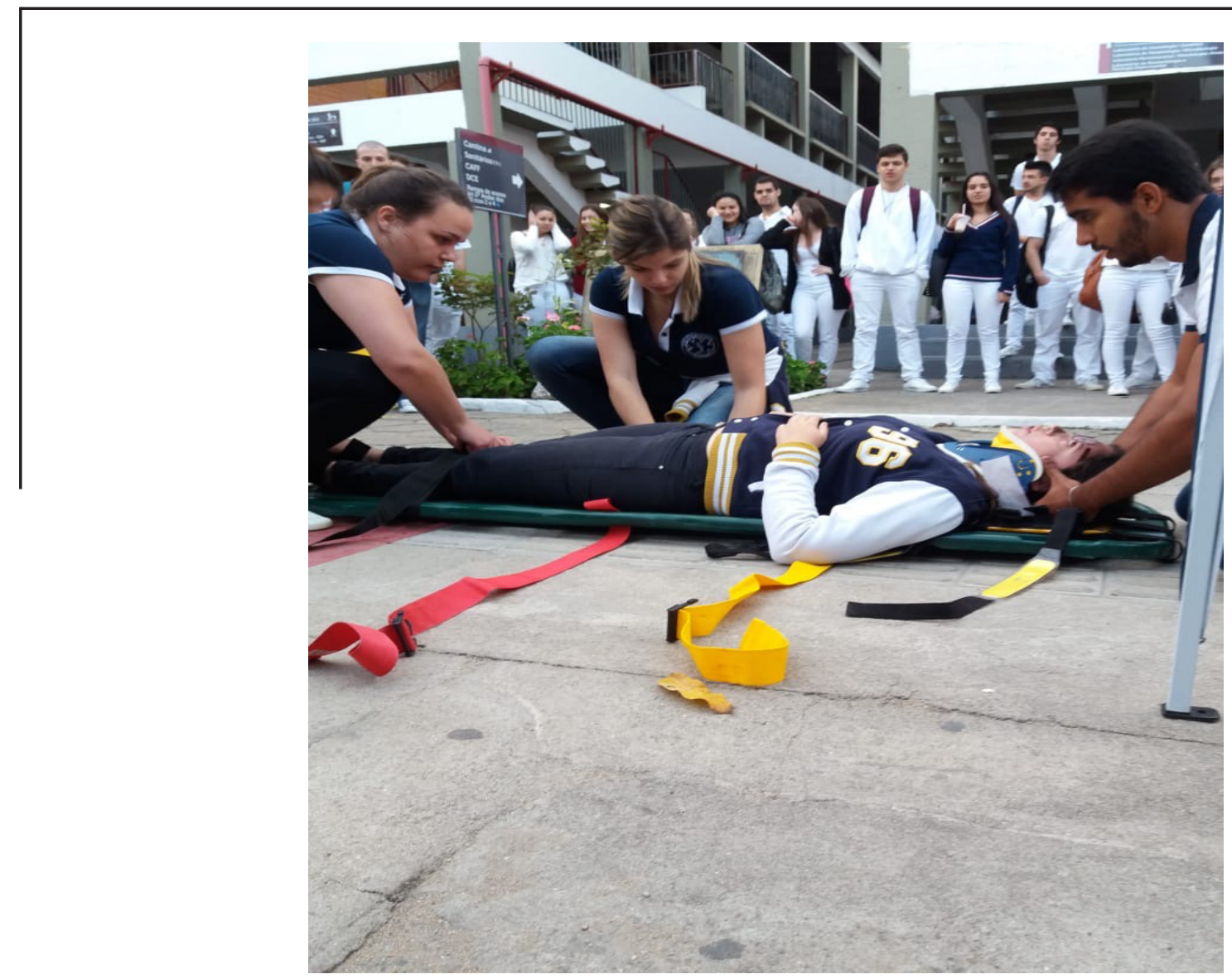

Figura 2. Simulação de um atendimento de primeiros socorros a um politraumatizado.

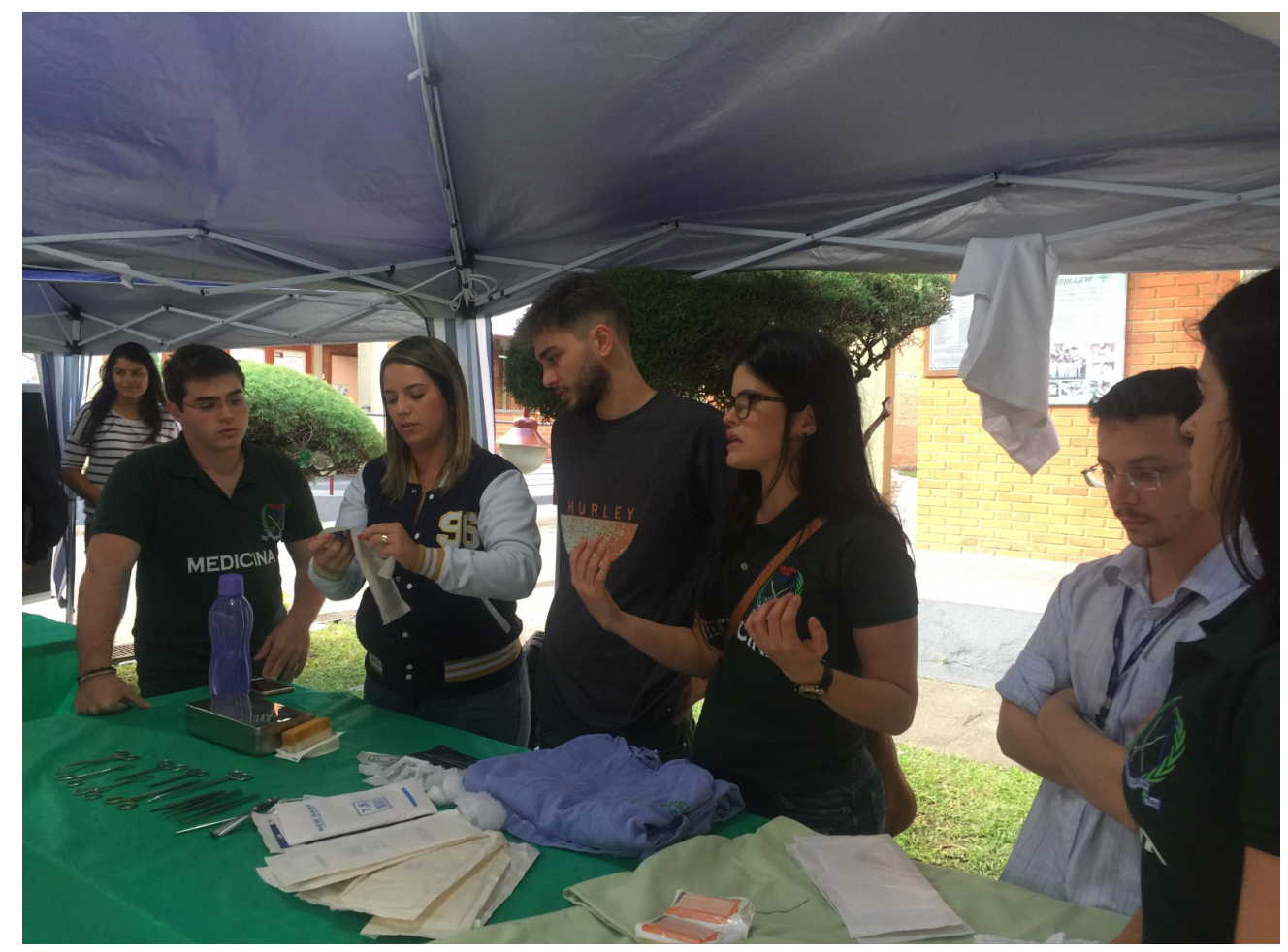

Figura 3. Apresentação dos materiais e demonstração das técnicas de suturas. 


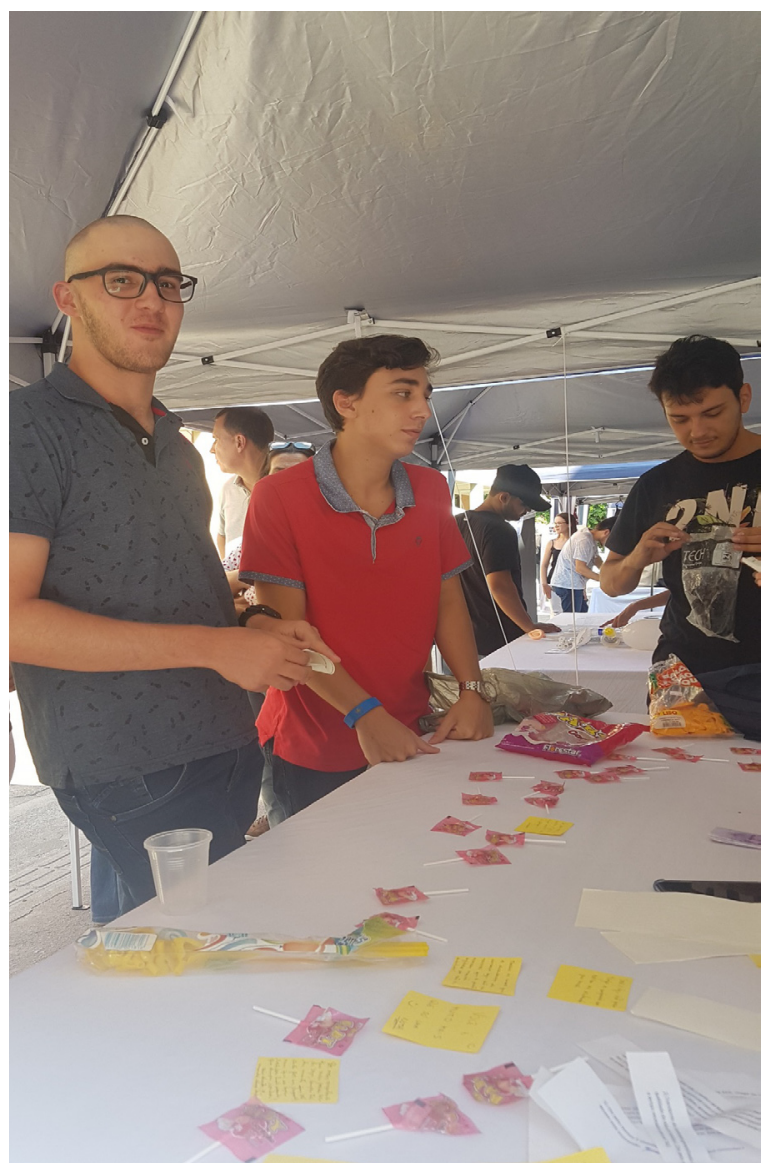

Figura 4. Jogos de perguntas e respostas com distribuição de brindes para os calouros.

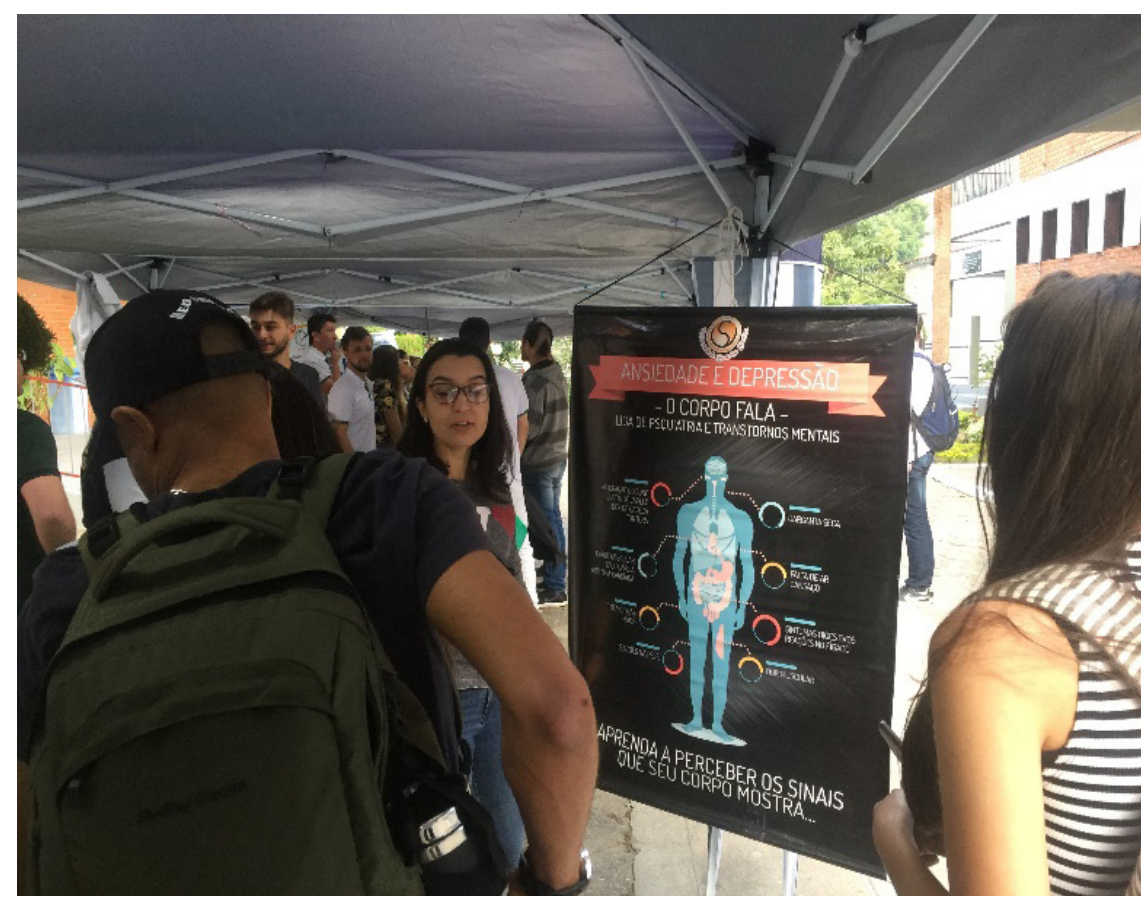

Figura 5. Liga mostrando como se apresentam os sinais de ansiedade pelo corpo. 


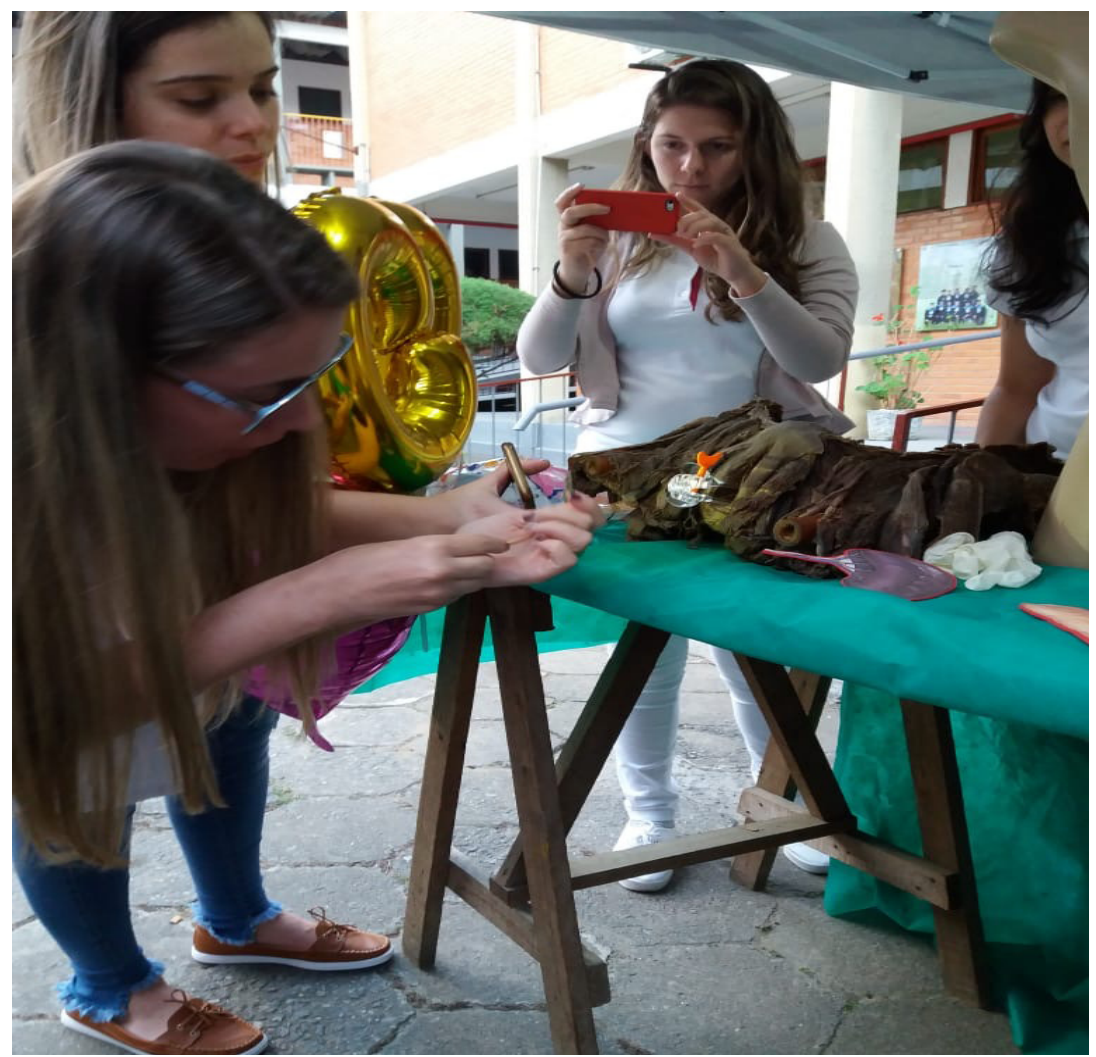

Figura 6. Simulação de coleta de exame de papanicolau em peça anatômica.

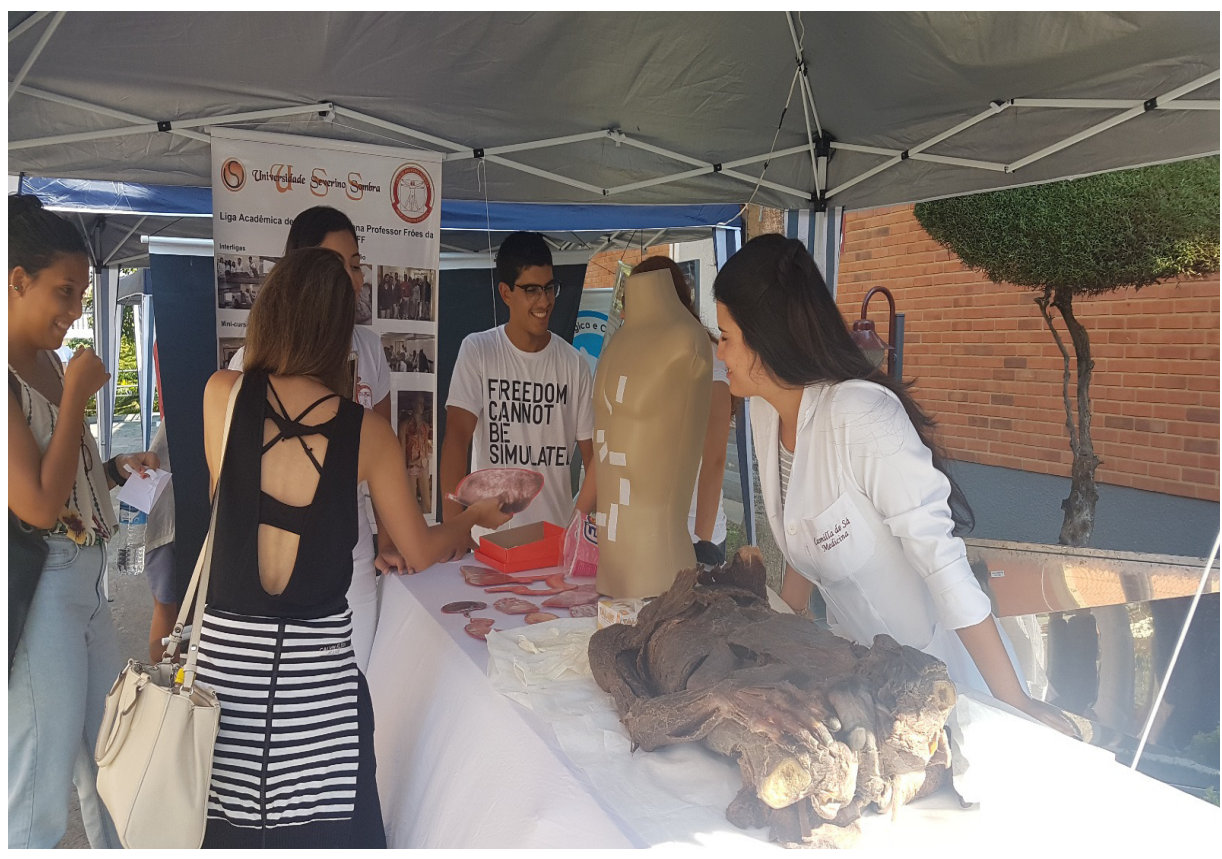

Figura 7. Jogo de posicionamento dos órgãos no corpo humano. 


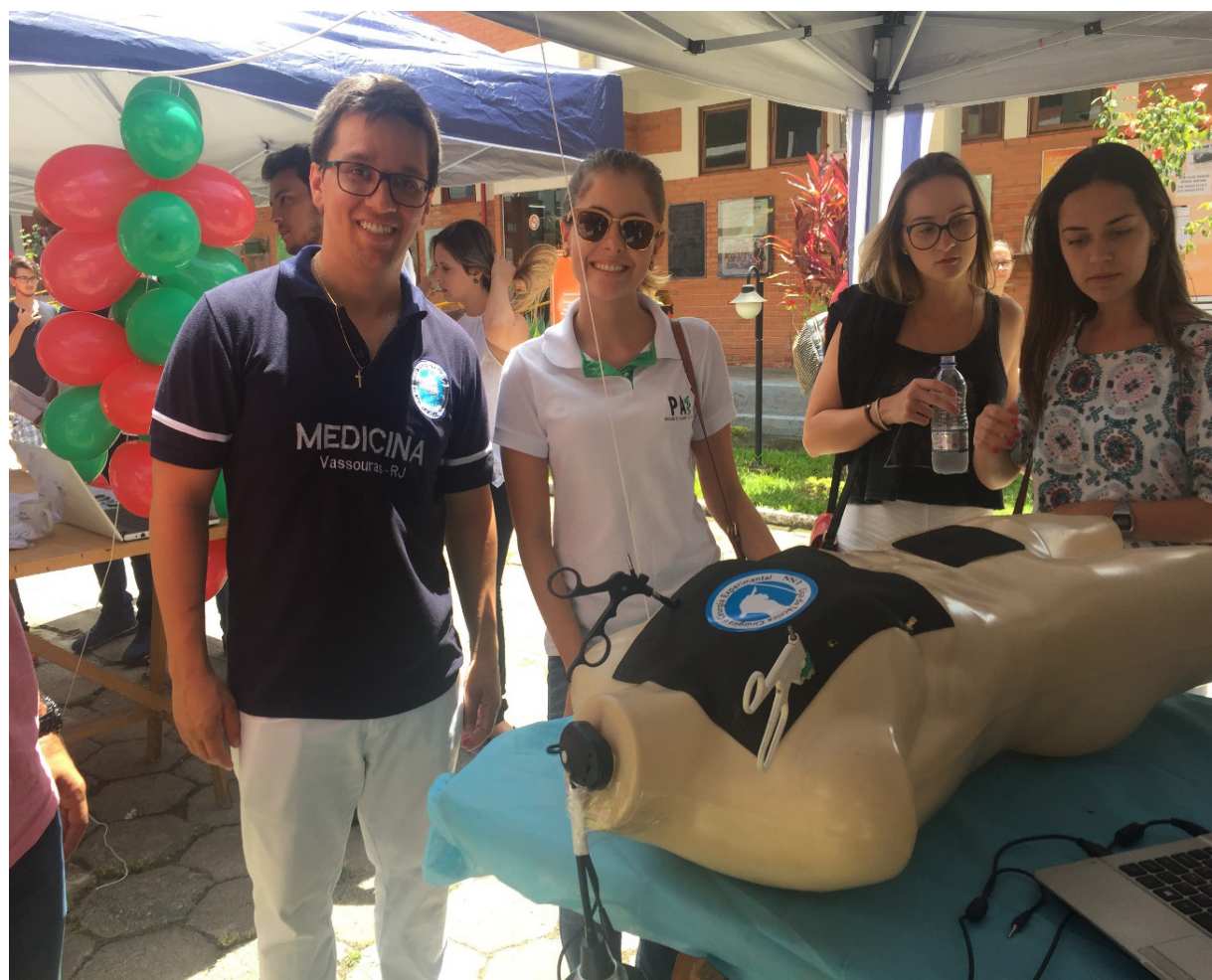

Figura 8. Apresentação e demonstração dos instrumentos e da técnica de laparoscopia.

\section{Resultados e Discussão}

Durante a "feira da calourada", os participantes observados pela equipe organizadora, ao serem abordados, mostravam-se engajados no seu novo projeto de vida e dispostos a aprender o máximo sobre seu curso e conhecer àquelas novas pessoas que se apresentavam a todo momento. Tanto que, mesmo sabendo da não obrigatoriedade de sua presença na feira, os novos alunos permaneceram até o final do eventoparticipando em todas as tendas e curiosos para conhecer o processo de ingresso em uma LA e nas atividades do curso de Medicina. Quatro alunos da nova turma chegaram a demonstrar interesse em participar da comissão organizadora do PAI no próximo semestre letivo. Fatos como esse,mostram claramente que a "feira da calourada" fez com que esses alunos se sentissem integrados com o ambiente, já no segundo dia de curso. Sentimento esse que normalmente poderia levar meses até que se percebessem como parte da universidade. Dessa forma, pode-se comprovar que o envolvimento do aluno em atividades extracurriculares é um importante instrumento de socialização? .

Ações de integração social e acadêmica desenvolvidas dentro e fora da universidade, influenciam a adaptação de estudantes universitários à instituição ${ }^{8,}$ 9. Um bom exemplo desse tipo de ação são as LAs. Também é evidenciado que alunos que se encontram melhor adaptados à instituição de ensino apresentam, inclusive, uma melhor percepção de sua saúde ${ }^{7}$.

A participação de novas atividades e o conhecimento de novas pessoas está associado a sentimentos positivos, que levam ao desenvolvimento pessoal e independência característicos da vida adulta no seu estágio inicial ${ }^{6,10}$.Nesse período da vida a aquisição de autonomia e auto confiança são fundamentais. Para que assim o aluno encontre sua capacidade que entre em consonância com o ambiente, se sentindo estimulado, caso contrário, a falta de motivação pode levar o aluno a ter dificuldades no ambiente acadêmico ${ }^{11}$.Encontrar um grupo que tenha idéias, comportamentos e interesses semelhantes pode ser tarefa árdua para um novo aluno universitário. Para que essa transição ocorra de forma mais fluida, participar de uma LA é uma boa opção.

A variedade de LAs apresentadas na feira continha características heterogêneas, que podiam atrair calouros com perfis variados.Dessa forma, os alunos ingressantes já puderam, na primeira semana de aula, descobrir um pouco do caráter diferenciado de algumas especialidades médicas disponíveis, e das ligas que integram a universidade, o que desperta desde o início da faculdade a busca porLAs que se aproximem do seu próprio perfil.

Dentre os alunos que participaram da feira, segundo a pesquisa, $84,31 \%$ dos afirmaram que o evento contribuiu para o seu acolhimento e integração com o curso e os alunos. Na questão em que os calouros eram perguntados como consideram as ligas acadêmicas 
como uma ferramenta de socialização e integração entre os alunos, $64,7 \%$ consideram as ligas acadêmicas como uma ferramenta muito importante de socialização e integração entre os alunos.

Apesar da maioria dos entrevistados terem demonstrado perceber valor nas LAs como forma de aproximação com os colegas, quando foram pedidos que dessem uma nota de 0 a 10 sobre o que o motivaria ou o motivou a ingressar em uma liga acadêmica, a maioria assinalou nota 10 para o item aproximação da prática médica $(74,5 \%)$ e pelo item interesse em uma área específica da medicina $(68,63 \%)$. Deixando os outros motivos, iniciação científica, aproximação com os professores e integração com veteranos e novas amizades, com notas menores.

\section{Considerações Finais}

As questões acerca do ingresso em um curso de ensino superior e as dificuldades enfrentadas pelos novos alunos certamente exigem maior aprofundamento. Esse tema envolve aspectos individuais como cultura, família, questões econômicas, entre outros. Porém, certos pontos são comuns a maioria destes estudantes, são exemplos o medo do desconhecido e o sentimento de solidão. Atuando com foco nesses pontos a "feira da calourada" mostrou estimular a aproximação dos alunos recém-chegados com seus veteranos e entre si. O evento apresentou as Ligas Acadêmicas aos estudantes, já os incentivando as atividades de ensino, pesquisa e extensão desenvolvidas pela universidade e pelo curso de Medicina. Desta forma, gradativamente e precocemente o contato com alunos mais experientes imprimiram um sentimento de acolhimento e segurança para iniciar o período letivo com menos dúvidas em relação às atividades acadêmicas desenvolvidas durante o curso.

\section{Referências bibliográficas}

Torres AR, Oliveira GM, Yamamoto FM, Lima MCP. Ligas acadêmicas e formação médica: contribuições e desafios. Revista Interface - Comunicação, Saúde, Educação. 2008;12(27):713-20.

Filho PDH. Ligas Acadêmicas: Motivações e Críticas aPropósito de um Repensar Necessário. Revista Brasileira de Educação Médica. 2011;35 (4): 535-543.

Ministério da Educação. Resolução CNE/CES n³, de 20 de junho de 2014. Diário Oficial da União, 201406 23; Seção 1: 8-11.

Cavalcante ASP, Vasconcelos MIO, Lira GV, Henriques RLM, Albuquerque INM, et al. As Ligas Acadêmicas na Área da Saúde: Lacunas do Conhecimento na Produção Científica Brasileira. Revista Brasileira de Educação Médica. 2018; 42 (1): 194-204.

Silva SA, Flores O. Ligas Acadêmicas no Processo de Formação dos Estudantes. Revista Brasileira de Educação Médica.2015; 39 (3): 410-425.

Oliveira CT, Dias ACG. Dificuldades na Trajetória Universitária e Rede de Apoio de Calouros e Formandos. Psico. 2014,abr-jun; 2 (45): $187-$ 197 .
Tavares CFV. Adaptação ao ensino superior, personalidade e otimismo em estudantes universitários do $1^{\circ}$ ciclo de estudos. [Dissertação]. Porto: Universidade Fernando Pessoa; 2014

Teixeira MAP, Castro AKSS, Zoltowiski APC. Integração acadêmica e integração social nas primeiras semanas na universidade: Percepções de estudantes universitários. Gerais: Revista Interestitucional de Psicologia. 2012; 5(11): 69-85

Porto MS, Soares AB. Diferenças entre expectativas e adaptação acadêmica de universitários de diversas áreas do conhecimento. Revista Análise Psicológica. 2017; 1 (35): 13-24.

Scopellti M, Tiberio L. Homesickness in university students: the role of multiple place attachment. Environmentandbehavior. 2010;42(3): 335-350.

Nadelson LS, Semmelroth C, Martinez G, Featherstone M, Fuhriman C A, Sell A. Why didcome here? - The influences and expectations of first-year students' college experience. HigherEducationStudies. 2013: 1 (3): 50-62. 